\title{
Implementation and Validation of an Analytical Method for Lincomycin Determination in Feathers and Edible Tissues of Broiler Chickens by Liquid Chromatography Tandem Mass Spectrometry
}

\author{
Aldo Maddaleno, ${ }^{1}$ Ekaterina Pokrant $\mathbb{D D}^{2}{ }^{2}$ Francisca Yanten, ${ }^{2}$ Betty San Martin, \\ and Javiera Cornejo $\left.{ }^{2}\right)^{2}$ \\ ${ }^{1}$ Laboratory of Veterinary Pharmacology, Faculty of Veterinary and Animal Sciences, University of Chile, \\ 8820808 Santiago, Chile \\ ${ }^{2}$ Food Safety Unit, Preventive Medicine Department, Faculty of Veterinary and Animal Sciences, University of Chile, \\ 8820808 Santiago, Chile
}

Correspondence should be addressed to Javiera Cornejo; jacornej@uchile.cl

Received 20 November 2018; Accepted 7 February 2019; Published 25 February 2019

Academic Editor: Josep Esteve-Romero

Copyright () 2019 Aldo Maddaleno et al. This is an open access article distributed under the Creative Commons Attribution License, which permits unrestricted use, distribution, and reproduction in any medium, provided the original work is properly cited.

\begin{abstract}
Recent studies have detected different antimicrobial residues in broiler chicken feathers, where they persisted for longer periods of time and at greater concentrations than in edible tissues. However, until today, lincomycin behaviour in this nonedible tissue has not been assessed yet. Considering this, an analytical methodology to detect and quantify this antibiotic concentration in feathers, muscle, and liver tissues from broiler chickens was implemented and in-house validated. The methodology will allow the determination of the bioaccumulation of this highly persistent antibiotic in feathers of treated birds. For this purpose, 98\% lincomycin and 95\% lincomycin D3 standards were used. Methanol was selected as the extraction solvent, and Chromabond ${ }^{\circledR}$ Florisil ${ }^{\circledR}$ cartridges were used for the clean-up stage. The separation of analytes was performed through the analytical column SunFire C18 with a running time of 4 minutes, and the instrumental analysis was performed through an LC-MS/MS, with a liquid chromatograph Agilent ${ }^{\circledR} 1290$ Infinity, coupled to an AB SCIEX ${ }^{\circledR}$ API 5500 mass spectrometer. An internal protocol for an in-house validation was designed based on recommendations from Commission Decision 2002/657/EC and the Guidance document on the estimation of limit of detection and limit of quantification for measurements in the field of contaminants in feed and food. The average retention time for lincomycin was $2.255 \mathrm{~min}$ (for quantifier ion, 126.0). The calibration curves showed a coefficient of determination $\left(r^{2}\right)$ greater than 0.99 for all matrices, while recovery levels ranged between $98 \%$ and $101 \%$. The limit of detection (LOD) calculated was of 19,22 , and $10 \mu \mathrm{g} \cdot \mathrm{kg}^{-1}$, and the limit of quantification (LOQ) was of 62,73 , and $34 \mu \mathrm{g} \cdot \mathrm{kg}^{-1}$ in feathers, muscle, and liver, respectively. This method detects lincomycin in the studied matrices, confidently and accurately, as it is required for designing analytical studies of drug residues in edible and nonedible tissues, such as feathers.
\end{abstract}

\section{Introduction}

Antimicrobials have been used therapeutically in diverse areas of animal farming for the treatment of different bacterial pathologies. Treating these animals not only controls pathogens affecting their own health, but it also helps to control human diseases. Additionally, antimicrobials have long been used with the intention of leveraging the efficiency of animal production [1].

Lincomycin is a natural antimicrobial belonging to the lincosamides class, and it is synthesised by Streptomyces lincolnensis bacteria. This drug is recommended for the 
treatment of diseases caused by aerobic and anaerobic Gram-positive infections, such as Staphylococcus spp. and Streptococcus spp. It is also used in association with other antimicrobial drugs to treat livestock infections caused by Bacteroides fragilis, as well as diseases of the respiratory tract in different animal species. The main mechanism of action of lincosamides focus on blocking protein synthesis in bacteria. It affects several activation steps of amino acid monomers via the aminoacyl-tRNA, as well as the processes of initiation, elongation, and termination of the polypeptide chains at the level of the bacterial ribosome [2].

Lincosamides and macrolides are first-choice antimicrobials that are used as bacteriostatic drugs in veterinary microbiology and as bactericidal drugs in farm animals [3]. However, using these antimicrobials in humans presents some risks due to their ability to cross different barriers, either in individuals or the environment, thereby helping to increase the selection of resistant bacteria at a global scale. Different surveillance studies have shown that foods of animal origin may present residues of these drugs, after it was administered to farm animals in several geographical areas $[4,5]$. These residues have even been found in both environment and in animals that were not treated with lincomycin themselves [6]. This finding proves that these residues are transferred from the production chain to the environment via organic waste, such as urine and faeces from treated animals or from other elements not yet qualified or quantified [6].

Several studies that have developed and validated methods according to EU Commission Decision 2002/657/ EC have pointed out that antibiotics can be detected in several edible tissues and other products like honey [7-9]. Specifically, lincomycin residues can be found in different animal products and tissues, such as muscle and plasma $[2,10-12]$. From this evidence, it is possible to infer that other animal structures, as feathers, could accumulate antimicrobial residues as well. In this regard, recent studies have used chromatographic methodologies to detect drug residues of veterinary importance. In those studies, researchers found that residues of enrofloxacin, flumequine, oxytetracycline, florfenicol, and tylosin were transferred to feathers of treated broiler chicken [13-17]. Furthermore, these residues were found for longer periods, and at higher concentrations, than those detected in edible tissues. Current regulations from the European Commission, aimed at controlling these drug residues in foods of animal origin, have set a maximum residue level (MRL) for lincomycin in any farm animal species: $100 \mu \mathrm{g} \cdot \mathrm{kg}^{-1}$ for muscle tissue, $50 \mu \mathrm{g} \cdot \mathrm{kg}^{-1}$ for fat tissue and eggs, $500 \mu \mathrm{g} \cdot \mathrm{kg}^{-1}$ for liver tissue, and $1500 \mu \mathrm{g} \cdot \mathrm{kg}^{-1}$ for kidney tissue, whereas for cattle milk, the MRL is $150 \mu \mathrm{g} \cdot \mathrm{kg}^{-1}$ [18]. Meanwhile, regulations from the Codex Alimentarius set a limit of $200 \mu \mathrm{g} \cdot \mathrm{kg}^{-1}$ for muscle tissue, $500 \mu \mathrm{g} \cdot \mathrm{kg}^{-1}$ for liver tissue, and $100 \mu \mathrm{g} \cdot \mathrm{kg}^{-1}$ for fat tissue, as well as $500 \mu \mathrm{g} \cdot \mathrm{kg}^{-1}$ and $1500 \mu \mathrm{g} \cdot \mathrm{kg}^{-1}$ for kidney tissue of poultry and swine, respectively [19]. Neither regulation includes poultry feathers, as these structures are not meant for direct consumption. However, residues from this antimicrobial could actually be present in them. Importantly, these by-products are currently being processed to prepare feather meal, which is used as an ingredient for animal diet formulations. Thus, it must be considered the possibility that these residues could be present in diets that include this ingredient as a food additive [20]. Bearing in mind the consequences that this residue may unleash if it is reintroduced in stage of the production chain, it becomes necessary to develop quantitative methodologies for analysis of lincomycin in feathers. A quantitative and confirmatory LC-MS/MS method will allow to avoid the reentrance of these antibiotic residues in the food chain. Several researchers have implemented methodologies on the basis of microbiological systems of chemiluminescent electromigration in different matrices; however, their results have not been optimum in terms of sensitivity and stability [21]. Other methodologies that have been attempted were based on immunochromatographic assays and are intended for the determination of lincomycin in milk, honey, muscle tissues, and urine [22]. In the case of LC-MS/MS, other researchers have tried using this kind of methodologies for the analysis of animal products, such as muscle tissue, honey, milk, and eggs [23-25]. For example, in a study reported by Jansen et al., the authors describe a qualitative methodology for the determination of several antimicrobials, including the lincomycin class [26]. However, it is important to also determine quantitatively the residues that could be transferred to feathers and other important matrices, such as liver and muscle tissue from birds that have been treated with this drug. Those results would allow that the behaviour of lincomycin could be determined in those by-products. Despite previous studies, they have determined the concentration and depletion time of different antibiotics in feathers [13-17]. Currently, the behaviour of lincomycin in this matrix has not been studied.

Lincomycin residues in feathers can become a re-entry path for these drug residues into the food chain, if they are used in the formulation of animal diets. The demonstrated persistence of different drug residues in feathers poses a risk to public health due to the probability of becoming an unknown route of antibiotic cross contamination. Love et al. described the risk related to the administration of contaminated feather meal in diets of food animals. In this study, of the 46 antimicrobials that were tested, over onethird $(n=17)$ were detected in feather meal samples. This information provides a clear overview about the trespassing of residues into feathers and the possibility to become a risk in the food chain [27]. Therefore, the implementation of an analytical method in feathers is critical to properly assess the bioaccumulation of this drug in this matrix.

In this work, we have implemented an optimized LCMS/MS analytical methodology. The method was validated according to an internal protocol based on Decision 2002/ $657 / \mathrm{EC}$ and the Guidance document on the estimation of limit of detection and limit of quantification for measurements in the field of contaminants in feed and food $[28,29]$. This method allowed to accurately and confidently quantify lincomycin residues in feathers and edible 
tissues from broiler chickens. This LC-MS/MS analytical methodology allows the quantification and confirmation of lincomycin in broiler chicken feathers, muscle, and liver.

\section{Materials and Methods}

2.1. Standard Solutions. A lincomycin standard of $98 \%$ certified purity-manufactured by Dr. Ehrenstorfer, $\mathrm{GmbH}$ (Augsburg, Germany) - and a lincomycin D3 standard of 95\% certified purity-manufactured by Toronto Research Chemicals (Toronto, Canada) - were used to prepare stock solutions by dissolving $1000 \mu \mathrm{g} \cdot \mathrm{mL}^{-1}$ of these compounds in a methanol/water $(50: 50)$ solution.

Working solutions were then prepared from the stock solutions by diluting $2000 \mathrm{ng} \cdot \mathrm{mL}^{-1}$ and $1000 \mathrm{ng} \cdot \mathrm{mL}^{-1}$ of lincomycin and lincomycin D3 solutions, respectively. All of these solutions were individually stored in microcentrifuge tubes at $-80^{\circ} \mathrm{C}$.

2.2. Chemicals and Reagent. Before the extraction stage, water was distilled and deionised in the laboratory using the Milli-Q ${ }^{\circledR}$ system with a resistance of less than $18.2 \mathrm{M} \Omega$ (Merck KGaA, Burlington, Massachusetts, USA).

This method also required reagents such as water, methanol, and acetonitrile. These reagents were of HPLCgrade purity and manufactured by J.T.Baker ${ }^{\circledR}$ (Avantor ${ }^{\circledR}$ Performance Materials LLC, Center Valley, PA) or a similar brand. Other reagents such as n-hexane, ethyl acetate, and acetic acid were of HPLC-grade purity and sourced from the line of LiChrosolv ${ }^{\circledR}$ solvents (Merck KGaA, Darmstadt, Germany). Meanwhile, ammonium acetate was of P.A. grade purity and sourced from the line of LiChrosolv ${ }^{\circledR}$ solvents (Merck KGaA, Darmstadt, Germany).

Solid-phase extraction cartridges were selected from the Chromabond $^{\circledR}$ Florisil $^{\circledR}$ line and manufactured by Macherey-Nagel GmbH and Co. KG (Düren, Germany).

2.3. Instrumentation. All samples were analysed using a liquid chromatograph device from the Agilent ${ }^{\circledR} 1290$ Infinity Series coupled to an AB Sciex ${ }^{\circledR}$ API 5500 triple quadrupole mass spectrometer (AB Sciex LLC, Framingham, MA), which was fitted with a SunFire ${ }^{\circledR}$ C18 analytical column of $3.5 \mu \mathrm{m} 2.1 \times 150 \mathrm{~mm}$ manufactured by Waters ${ }^{\circledR}$ (Waters Corporation, Milford, MA). The chromatographic separation procedure involved a mobile phase at $\mathrm{pH}$ $3.5 \pm 0.2$ made from two solvents $(65 \%$ solvent A, 35\% solvent B). Solvent A was a solution of $0.02 \%$ ammonium acetate at $\mathrm{pH} 4.5 \pm 0.05$, whereas solvent $\mathrm{B}$ was a solution of $0.1 \%$ acetic acid in acetonitrile. The gradient flow was set at $200 \mu \mathrm{l} \cdot \mathrm{min}^{-1}$, the gradient elution was from 0 to 4 minutes ( $65 \%$ solvent $A, 35 \%$ solvent $\mathrm{B}$ ), the injection volume was $5 \mu \mathrm{L}$, and the column oven temperature was of $30^{\circ} \mathrm{C}$. Table 1 lists the parameters used for the operation of the mass detector. Table 2 lists the ion masses that were monitored in this study.
TABLE 1: Operation parameters of the MS/MS detector.

\begin{tabular}{lc}
\hline Parameter & Analytical conditions \\
\hline Ionisation & ESI \\
Scan type & MRM \\
TEM & $500^{\circ} \mathrm{C}$ \\
GS1 & $60 \mathrm{psi}$ \\
GS2 & $40 \mathrm{psi}$ \\
CUR & $25 \mathrm{psi}$ \\
CAD & $8 \mathrm{psi}$ \\
IS & $3600 \mathrm{~V}$ \\
Total scan time & $1.62 \mathrm{sec}$ \\
\hline
\end{tabular}

ESI: electrospray ionisation; MRM: multiple reaction monitoring; TEM: source temperature; GS1: nebuliser; GS2: turbo ion; CUR: curtain gas; CAD: collision gas; ISV: ion spray voltage.

Lastly, the equipment was managed and integrated using the Analyst ${ }^{\circledR}$ 1.6.3 (AB Sciex LLC, Framingham, MA) and MultiQuant $^{\circledR} 3.0$ (AB Sciex LLC, Framingham, MA) software packages, respectively.

2.4. Sample Processing. Samples were sourced from commercial broiler chickens and were first analysed by HPLCMS/MS to confirm the absence of lincomycin residues. Feather samples were cryogenically treated with liquid nitrogen to ease their grinding in a Robot Coupe ${ }^{\circledR} \mathrm{R} 4$ "tabletop cutter" food processor (Robot Coupe ${ }^{\circledR}$, Vincennes, France). Likewise, muscle and liver tissue samples were also ground in the food processor, though no liquid nitrogen processing was required for those samples.

2.5. Extraction Procedure for Feathers, Muscle, and Liver Samples. The extraction of lincomycin residues from feather samples began by weighing in $1.00 \pm 0.01 \mathrm{~g}$ of each sample in a $50 \mathrm{~mL}$ polypropylene tube. These samples were then fortified with the lincomycin standard, as well as the lincomycin D3 internal standard. Subsequently, $40 \mathrm{~mL}$ of HPLC-grade methanol were added to the sample tubes before these were shaken in a Multi Reax ${ }^{\circledR}$ agitator (Heidolph Instruments $\mathrm{GmbH}$ and Co. KG, Schwabach, Germany). Afterwards, tubes were sonicated and centrifuged in a Hettich ${ }^{\circledR}$ ROTOFIX 32A centrifuge (Hettich Lab Technology, Beverly, Massachusetts) at 2,700 $\mathrm{g}$ for 15 minutes for feathers, 10 minutes for muscle, and 15 minutes for liver samples. The resulting supernatant was filtered through glass fibre and then passed at a flow rate of $1 \mathrm{~mL} \cdot \mathrm{min}^{-1}$ through a Chromabond ${ }^{\circledR}$ Florisil ${ }^{\circledR}$ cartridge (Macherey-Nagel GmbH and Co. KG, Düren, Germany). This cartridge was previously conditioned with $10 \mathrm{~mL}$ of HPLC-grade hexane and $10 \mathrm{~mL}$ of a solution $(8: 2)$ of HPLC-grade methanol and HPLC-grade ethyl acetate. This filtrate was collected in a $50 \mathrm{~mL}$ falcon tube and then evaporated, under a mild nitrogen flow, in a water bath set at a temperature of $40-50^{\circ} \mathrm{C}$. Samples were reconstituted in $500 \mu \mathrm{L}$ of a solution $(9: 1)$ of methanol and HPLC-grade water. Once reconstituted, samples were shaken, sonicated, and centrifuged in a VWR ${ }^{\circledR}$ 2417R (Avantor, Radnor, PA) device at 17,136g for 5 minutes for feathers, 5 minutes for muscle, and 10 minutes for liver samples. Finally, samples were transferred to a glass 
TABle 2: Monitored ion masses.

\begin{tabular}{|c|c|c|c|c|c|c|c|}
\hline Analyte & Precursor ion (Q1 mass) (Da) & Fragment ion (Q3 mass) (Da) & Time (ms) & $\mathrm{DP}(\mathrm{V})$ & $\mathrm{EP}(\mathrm{V})$ & CE (V) & $\mathrm{CXP}(\mathrm{V})$ \\
\hline Lincomycin 1 & 407.0 & 126.0 & 400.0 & 26.0 & 6.0 & 30.0 & 12.0 \\
\hline Lincomycin 2 & 407.0 & 359.0 & 400.0 & 26.0 & 6.0 & 27.0 & 4.0 \\
\hline Lincomycin D3 1 & 410.0 & 129.0 & 400.0 & 26.0 & 6.0 & 30.0 & 12.0 \\
\hline Lincomycin D3 2 & 410.0 & 362.0 & 400.0 & 26.0 & 6.0 & 27.0 & 12.0 \\
\hline
\end{tabular}

Q1: quadrupole 1; Q3: quadrupole 3; Da: dalton; DP: declustering potential; EP: entrance potential; CE: collision energy; CXP: collision cell exit potential; V: volt. The precursor ion 410.0/362.0 of lincomycin D3 was used for quantification of the analyte in all samples.

vial using a Millex ${ }^{\circledR}$ (Merck KGaA, Burlington, Massachusetts, USA) $33 \mathrm{~mm}$ polyvinylidene fluoride (PVDF) sterile filter syringe.

The extraction procedure for muscle and liver samples followed the same principles than the protocol designed for feather samples, with the sole exceptions of using $20 \mathrm{~mL}$ of solvent for the methanol extraction step and that samples were not prefiltered through glass wool before passing through the Chromabond ${ }^{\circledR}$ Florisil ${ }^{\circledR}$ cartridges (MachereyNagel GmbH and Co. KG, Düren, Germany).

2.6. Validation Procedure. To complete the in-house validation of these analytical methods was followed an internal protocol specially designed for this study based on recommendations from the European Commission Decision 2002/657/EC and the Guidance document on the estimation of limit of detection and limit of quantification for measurements in the field of contaminants in feed and food $[28,29]$. Due to the impact that could have contaminations with pharmaceutical residues in products used as additives in the feeding of animals destined for consumption, it was decided that these guides offered the minimum analytical base to establish the statistical parameters of the methodology and to accomplish with the current regulations focused on this type of analysis.

This single validation assessed parameters such as recovery performance, precision (measured as repeatability and intralaboratory reproducibility), linearity, retention time, limit of detection (LOD), and limit of quantification (LOQ).

To assess recovery performance, all samples of feather, muscle, and liver tissues were analysed to certify them as blank, ruling out any contamination with lincomycin residues. Then, samples were fortified at $0.2,0.8$, and 1.6 times the MRL, which has been set at $100 \mu \mathrm{g} \cdot \mathrm{kg}^{-1}$ by European Commission for muscle tissue (37/2010/EC) [18]. With this value selection of $20 \mu \mathrm{g} \cdot \mathrm{kg}^{-1}$, all the types of samples were analysed with a detection limit under the MRL set for muscle by the European Commission and in a level that allows to reliably detect low concentrations of the residue in feathers. The recovery performance of the extraction stage for each level was calculated by comparing samples results against those from injections of pure standard solutions at the same concentration level.

Precision was assessed by its components: repeatability and intralaboratory reproducibility. In the case of repeatability, six sample sets were fortified and processed at three different concentration levels $\left(20,80\right.$, and $\left.160 \mu \mathrm{g} \cdot \mathrm{kg}^{-1}\right)$, on the same day. Meanwhile, intralaboratory reproducibility was measured by using six sample sets, fortified at the same concentration levels than for the repeatability assessment, but these were analysed on different days and by different analysts.

As for the linearity of these methods, it was assessed by plotting calibration curves for each matrix, at five different concentration levels $\left(20,40,80,120\right.$, and $\left.160 \mu \mathrm{g} \cdot \mathrm{kg}^{-1}\right)$.

The selectivity and specificity of these methods were assessed by analysing blank samples of feather, muscle, and liver tissues from different sources. LOD and LOQ were determined on the basis of 10 spiked blank samples of each matrix. The criteria for selecting the LOD of this method was to achieve a signal-to-noise ratio greater than $3: 1$, whereas the LOQ is the concentration that gives a signal-to-noise ratio greater than $10: 1$.

\section{Results and Discussion}

3.1. Method Development and Optimization. As mentioned before, our research group developed a method for detection of lincomycin residues in feathers, muscle, and liver tissues and in-house validated it based on the recommendations described in the Commission Decision 2002/657/EC and Guidance document on the estimation of limit of detection and limit of quantification for measurements in the field of contaminants in feed and food [28, 29].

A quick, easy, and inexpensive extraction methodology enhances the capability of every laboratory to implement any analytical method that might be technically qualified to perform. The method implemented in this work allows for the simultaneous analysis of three different matrices to detect lincomycin residues, and it does not require modifications of any of the chromatographic conditions of the mass spectrometer. Is important to emphasise that the SunFire ${ }^{\circledR}$ C18 chromatographic column was selected for this particular method due to its resolution, being able to distinguish among interfering residues with similar molecular weights and chemical characteristics. Such versatility enhanced the specificity of the analytical method.

The solvents that were used for the extraction stage are the base for several methodologies. Using such solvents for the implementation of this method greatly facilitates its adoption in most analytical laboratories that currently work with chromatographic techniques. The fact that this method provides robust results in these three matrices, with only a few modifications in methanol extraction volume and glass fibre prefiltration, also favours 
TABLE 3: Average retention time and relative standard deviation (RSD) of monitored ion masses of lincomycin and lincomycin D3 residues.

\begin{tabular}{lcccc}
\hline Analyte & Precursor ion (Da) & Fragment ion (Da) & Average RT (min) & RSD (\%) \\
\hline \multirow{2}{*}{ Lincomycin } & 407.0 & $126.0^{*}$ & 2.255 & 0.24 \\
& & $359.0^{* *}$ & 2.247 & 0.36 \\
\hline Lincomycin D3 & 410.0 & 362.0 & 2.237 & 0.23 \\
\hline
\end{tabular}

Da: dalton; RT: retention time; RSD: relative standard deviation; * quantifier ion; ${ }^{* *}$ confirmatory ion.

its suitability for simultaneously analysing all these matrices.

The method detected residues using chromatographic techniques, monitoring their masses and specific retention times. Table 3 specifically lists average retention times and coefficients of variation for six analyses of certified standards of lincomycin and lincomycin D3. Fragment ion 407.0/126.0 was used to quantify lincomycin in all three matrices, whereas ion $407.0 / 359.0$ was confirmatory due to its chromatographic intensity.

3.2. Selectivity and Specificity. No interfering signals were detected in any of the three matrices, around the retention time that is characteristic of lincomycin residues, for the sample group comprising 20 blank samples from different sources (Figure 1). Therefore, this parameter met the acceptance criteria, being the specific method for the three study matrices.

3.3. Detection Range. The LOD was set at 19,22 , and $10 \mu \mathrm{g} \cdot \mathrm{kg}^{-1}$ for feather, muscle, and liver, with a signal-tonoise ratio greater than $3: 1$ for the three matrices. Our results indicated that for 10 repetitions (fortified at $20 \mu \mathrm{g} \cdot \mathrm{kg}^{-1}$ ) in all matrices (Figure 2), the relative standard deviation of the replicates was less than $10 \%$, which accomplished the acceptance criteria for the parameter.

The LOQ was defined as 3.3 times the LOD previously calculated with the deviation standard of the 10 repetitions. These values for LOQ were accepted because they reached a signal-to-noise ratios greater than $10: 1$ for the analyte in all matrices. Table 4 lists the LOD, average concentrations detected from these 10 samples (fortified at $20 \mu \mathrm{g} \cdot \mathrm{kg}^{-1}$ ), as well as their respective standard deviations, relative standard deviation (RSD), and LOQ for the three matrices.

3.4. Calibration Curves. Each calibration curve comprised five concentration levels: $20,40,80,120$, and $160 \mu \mathrm{g} \cdot \mathrm{kg}^{-1}$. These concentration points in the calibration curve were determined to explore the lincomycin levels in feathers because there is no previous information regarding concentrations in this matrix or a reference value to follow Thus, the selection of $20 \mu \mathrm{g} \cdot \mathrm{kg}^{-1}$ as a first point of the calibration curve to determinate the levels of the residue in feathers was used like an explorative value and no has relation with the actual MRL in muscle and liver.

The slope is the most useful parameter for the analysis of linear equations, as it provides the best information about sensitivity of analytical methods and their quantification capabilities. Thus, we calculated these slopes, as well as their coefficient of variation. Our results showed that the coefficients of determination $\left(r^{2}\right)$ for the calibration curves were higher than 0.99 , and their coefficients of variation were lower than $25 \%$. Therefore, the acceptance criteria were met, and a high sensitivity was achieved in the three study matrices. Table 5 lists the average of coefficients of determination, slope average, and their respective coefficient of variation, for all matrices.

3.5. Recovery and Precision. Recovery percentages for all matrices averaged between $98.47 \%$ and $100.67 \%$. The results obtained meet the acceptance criteria since they fall within the range indicated by the Commission Decision 2002/65/ EC, which corresponds to values between $80 \%$ and $110 \%$. Therefore, this method has a reliability sufficient to quantify lincomycin in feathers, muscle, and liver.

In the case of the precision, the obtained results for repeatability did not exceed the values of intralaboratory reproducibility, and this did not exceed an RSD of $23 \%$. Table 6 shows average recoveries as well as their respective RSD for these three matrices, according to their working concentration. In addition, the results of the precision through repeatability and intralaboratory reproducibility are shown.

Therefore, all parameters accomplished the acceptance criteria set by the European Commission 2002/657/EC and the Guidance document on the estimation of limit of detection and limit of quantification for measurements in the field of contaminants in feed and food for the detection of lincomycin in these matrices accurately and reliably.

\section{Conclusions}

In the present study, a confirmatory analytical method for detecting lincomycin in feathers, muscle, and liver samples was developed and in-house validated. This analytical method is reliable and capable of determining residue concentrations in these matrices. Furthermore, they exhibit results meet the criteria set forth by the Commission Decision 2002/657/EC and the Guidance document on the estimation of limit of detection and limit of quantification for measurements in the field of contaminants in feed and food. Therefore, this work could become the basis for future research on the behaviour of lincomycin in feathers sourced from birds that have received therapeutic doses of this drug. The confirmatory nature of this LC-MS/MS analytical method makes it a reliable tool for developing further studies to determine the behaviour, transfer, and depletion of lincomycin in feathers, muscle, and liver from broiler chickens. This study is essential for the development of control 


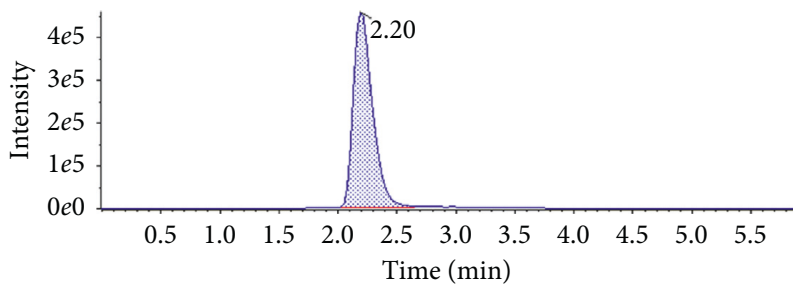

(a)

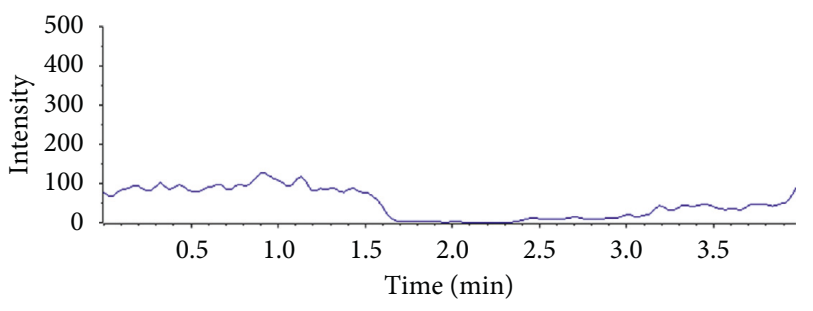

(c)

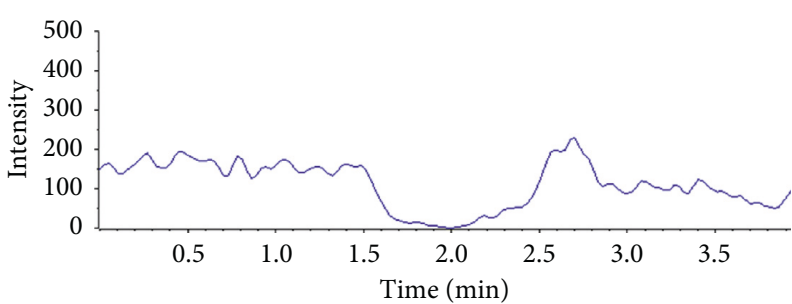

(b)

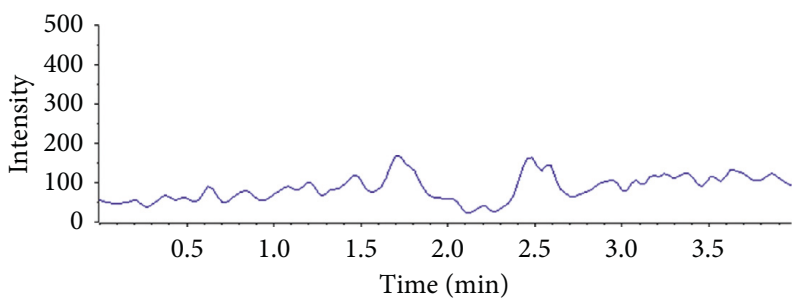

(d)

FIgURe 1: Chromatograms of lincomycin from (a) a pure standard solutions injection, (b) a blank feather sample, (c) a blank muscle sample, and (d) a blank liver sample.

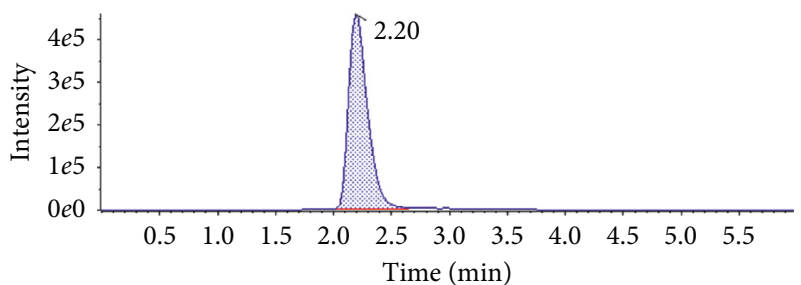

(a)

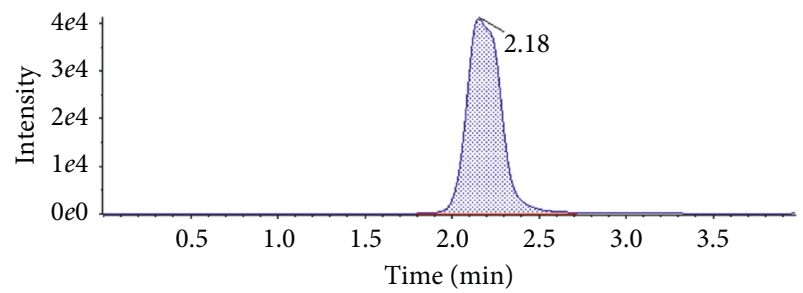

(c)

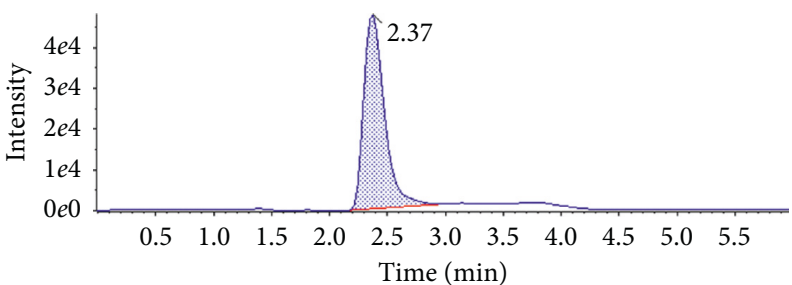

(b)

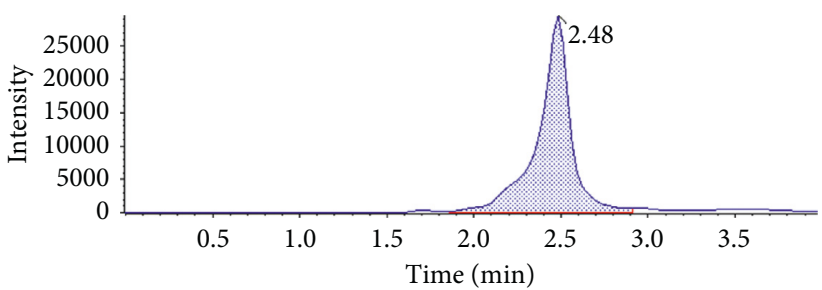

(d)

Figure 2: Chromatograms of lincomycin (a) from lincomycin pure standard injection and (b) feather, (c) muscle, and (d) liver samples fortified with lincomycin standard at a concentration of $20 \mu \mathrm{g} \cdot \mathrm{kg}^{-1}$.

TABLE 4: Limit of detection (LOD), average concentration (calculated from 20 samples fortified up to the LOD concentration), standard deviation (SD), relative standard deviation (RSD), and limit of quantification (LOQ) for lincomycin in samples of feather, muscle, and liver tissues.

\begin{tabular}{lccccc}
\hline Biological matrix & LOD $\left(\mu \mathrm{g} \cdot \mathrm{kg}^{-1}\right)$ & Average concentration $\left(\mu \mathrm{g} \cdot \mathrm{kg}^{-1}\right)$ & SD & RSD $(\%)$ & LOQ $\left(\mu \mathrm{g} \cdot \mathrm{kg}^{-1}\right)$ \\
\hline Feather & 19 & 20.80 & 1.52 & 7.29 & 62 \\
Muscle & 22 & 21.09 & 0.17 & 0.78 & 73 \\
Liver & 10 & 21.80 & 2.17 & 9.96 & 34 \\
\hline
\end{tabular}

TABLE 5: Method linearity parameters for three calibration curves: $r^{2}$ average, slope average, and their respective relative standard deviation (RSD) for lincomycin, by biological matrix.

\begin{tabular}{|c|c|c|c|c|}
\hline Biological matrix & $r^{2}$ average & RSD (\%) & Slope average & RSD (\%) \\
\hline Feather & 0.998 & 0.13 & 0.241 & 1.63 \\
\hline Muscle & 0.999 & 0.01 & 0.029 & 1.44 \\
\hline Liver & 0.995 & 0.15 & 0.650 & 4.33 \\
\hline
\end{tabular}


TABLE 6: Precision parameters: repeatability, intralaboratory reproducibility, and average recovery rate with their respective relative standard deviation (RSD), for each biological matrix, at concentrations of 20,80 , and $160 \mu \mathrm{g} \cdot \mathrm{kg}^{-1}$.

\begin{tabular}{|c|c|c|c|c|c|}
\hline Biological matrix & $\begin{array}{c}\text { Working concentration } \\
\left(\mu \mathrm{g} \cdot \mathrm{kg}^{-1}\right)\end{array}$ & $\begin{array}{c}\text { Repeatability } \\
\text { RSD (\%) }\end{array}$ & $\begin{array}{c}\text { Intralaboratory reproducibility } \\
\text { RSD (\%) }\end{array}$ & Average recovery & Recovery RSD (\%) \\
\hline \multirow{3}{*}{ Feathers } & 20 & 6.6 & 9.1 & 100.02 & 0.06 \\
\hline & 80 & 2.9 & 4.0 & 99.99 & 0.03 \\
\hline & 160 & 0.6 & 0.8 & 100.00 & 0.01 \\
\hline \multirow{3}{*}{ Muscle } & 20 & 6.9 & 11.2 & 98.78 & 0.04 \\
\hline & 80 & 3.0 & 4.8 & 100.53 & 0.02 \\
\hline & 160 & 0.6 & 1.0 & 99.89 & 0.004 \\
\hline \multirow{3}{*}{ Liver } & 20 & 12.5 & 20.7 & 98.47 & 0.09 \\
\hline & 80 & 5.1 & 8.5 & 100.67 & 0.04 \\
\hline & 160 & 1.1 & 1.9 & 99.86 & 0.01 \\
\hline
\end{tabular}

measures and surveillance strategies that assess lincomycin residues in this by-product.

\section{Data Availability}

The data used to support the findings of this study are available from the corresponding author upon request.

\section{Conflicts of Interest}

The authors declare that there are no conflicts of interest regarding the publication of this paper.

\section{Acknowledgments}

This work was supported by CONICYT (Comisión Nacional de Investigación Científica y Tecnológica) via the FONDECYT Initiation into Research (grant no. 11140530).

\section{References}

[1] V. Goetting, K. A. Lee, and L. A. Tell, "Pharmacokinetics of veterinary drugs in laying hens and residues in eggs: a review of the literature," Journal of Veterinary Pharmacology and Therapeutics, vol. 34, no. 6, pp. 521-556, 2011.

[2] S. Gouri, D. Venkatachalam, and V. Dumka, "Pharmacokinetics of lincomycin following single intravenous administration in buffalo calves," Tropical Animal Health and Production, vol. 46, no. 6, pp. 1099-1102, 2014.

[3] J. Spížek and T. Řezanka, "Lincosamides: chemical structure, biosynthesis, mechanism of action, resistance, and applications," Biochemical Pharmacology, vol. 133, pp. 20-28, 2017.

[4] R.-W. Han, Z.-N. Yu, T.-Y. Zhen, and J. Wang, "Survey of veterinary drug residues in raw milk in Hebei Province, China," Journal of Food Protection, vol. 80, no. 11, pp. 1890-1896, 2017.

[5] N. G. Dodder, K. A. Maruya, P. Lee Ferguson et al., "Occurrence of contaminants of emerging concern in mussels (mytilus spp.) along the California coast and the influence of land use, storm water discharge, and treated wastewater effluent," Marine Pollution Bulletin, vol. 81, no. 2, pp. 340-346, 2014.

[6] L. M. Chiesa, M. Nobile, R. Malandra, S. Panseri, and F. Arioli, "Occurrence of antibiotics in mussels and clams from various FAO areas," Food Chemistry, vol. 240, pp. 16-23, 2018.

[7] K. Tayeb-Cherif, J. Peris-Vicente, S. Carda-Broch, and J. Esteve-Romero, "Use of micellar liquid chromatography to analyze oxolinic acid, flumequine, marbofloxacin and enrofloxacin in honey and validation according to the 2002/657/ EC decision," Food Chemistry, vol. 202, pp. 316-323, 2016.

[8] D. Terrado-Campos, K. Tayeb-Cherif, J. Peris-Vicente, S. Carda-Broch, and J. Esteve-Romero, "Determination of oxolinic acid, danofloxacin, ciprofloxacin, and enrofloxacin in porcine and bovine meat by micellar liquid chromatography with fluorescence detection," Food Chemistry, vol. 221, pp. 1277-1284, 2017.

[9] J. Peris-Vicente, K. Tayeb-Cherif, S. Carda-Broch, and J. Esteve-Romero, "Validation of a procedure to quantify oxolinic acid, danofloxacin, ciprofloxacin and enrofloxacin in selected meats by micellar liquid chromatography according to EU commission decision 2002/657/EC," Electrophoresis, vol. 38, no. 16, pp. 2011-2017, 2017.

[10] S. Adams, R. Fussell, M. Dickinson, S. Wilkins, and M. Sharman, "Study of the depletion of lincomycin residues in honey extracted from treated honeybee (Apis mellifera L.) colonies and the effect of the shook swarm procedure," Analytica Chimica Acta, vol. 637, no. 1-2, pp. 315-320, 2009.

[11] J. He, N. Wu, P. Luo et al., "Development of a heterologous enzyme-linked immunosorbent assay for the detection of clindamycin and lincomycin residues in edible animal tissues," Meat Science, vol. 125, pp. 137-142, 2017.

[12] G. A. Albarellos, L. Montoya, G. A. A. Denamiel, M. C. Velo, and M. F. Landoni, "Pharmacokinetics and bone tissue concentrations of lincomycin following intravenous and intramuscular administrations to cats," Journal of Veterinary Pharmacology and Therapeutics, vol. 35, no. 6, pp. 534-540, 2011.

[13] B. S. Martín, J. Cornejo, D. Iragüen, H. Hidalgo, and A. Anadón, "Depletion study of enrofloxacin and its metabolite ciprofloxacin in edible tissues and feathers of white leghorn hens by liquid chromatography coupled with tandem mass spectrometry," Journal of Food Protection, vol. 70, no. 8, pp. 1952-1957, 2007.

[14] J. Cornejo, L. Lapierre, D. Iragüen, N. Pizarro, H. Hidalgo, and B. San Martín, "Depletion study of three formulations of flumequine in edible tissues and drug transfer into chicken feathers," Journal of Veterinary Pharmacology and Therapeutics, vol. 34, no. 2, pp. 168-175, 2011.

[15] J. Cornejo, E. Pokrant, M. Krogh et al., "Determination of oxytetracycline and 4-epi-oxytetracycline residues in feathers and edible tissues of broiler chickens using liquid chromatography coupled with tandem mass spectrometry," Journal of Food Protection, vol. 80, no. 4, pp. 619-625, 2017.

[16] J. Cornejo, E. Pokrant, R. Riquelme et al., "Single-laboratory validation of an LC-MS/MS method for determining 
florfenicol (FF) and florfenicol amine (FFA) residues in chicken feathers and application to a residue-depletion study," Food Additives \& Contaminants: Part A, vol. 34, no. 4, pp. 469-476, 2016.

[17] J. Cornejo, E. Pokrant, C. Carvallo, A. Maddaleno, and B. San Martín, "Depletion of tylosin residues in feathers, muscle and liver from broiler chickens after completion of antimicrobial therapy," Food Additives \& Contaminants: Part A, vol. 35, no. 3, pp. 448-457, 2017.

[18] The European Commission, "Commission regulation (EU) no. 37/2010 of 22 December 2009 on pharmacologically active substances and their classification regarding maximum residue limits in foodstuffs of animal origin," Official Journal of the European Union, vol. L15, pp. 1-72, 2009.

[19] Codex Alimentarius, "Maximum residue limits (MRLS) and risk management recommendations (RMRS) for residues of veterinary drugs in foods," CAC/MRL 2, 2017.

[20] C. Arunlertaree and C. Moolthongnoi, "The use of fermented feather meal for replacement fish meal in the diet of Oreochromis niloticus," Environment and Natural Resources Journal, vol. 6, no. 1, pp. 13-24, 2008.

[21] S. Cao, S. Song, L. Liu, N. Kong, H. Kuang, and C. Xu, "Comparison of an enzyme-linked immunosorbent assay with an immunochromatographic assay for detection of lincomycin in milk and honey," Immunological Investigations, vol. 44, no. 5, pp. 438-450, 2015.

[22] J. Zhou, K. Zhu, F. Xu et al., "Development of a microspherebased fluorescence immunochromatographic assay for monitoring lincomycin in milk, honey, beef, and swine urine," Journal of Agricultural and Food Chemistry, vol. 62, no. 49, pp. 12064-12066, 2014.

[23] M. Solliec, D. Massé, and S. Sauvé, "Analysis of trimethoprim, lincomycin, sulfadoxin and tylosin in swine manure using laser diode thermal desorption-atmospheric pressure chemical ionization-tandem mass spectrometry," Talanta, vol. 128, pp. 23-30, 2014.

[24] A. Tolgyesi, J. Fekete, S. Fekete, V. K. Sharma, K. Bekesi, and E. Toth, "Analysis of sub $\mathrm{g} / \mathrm{kg}$ lincomycin in honey, muscle, milk, and eggs using fast liquid chromatography-tandem mass spectrometry," Journal of Chromatographic Science, vol. 50, no. 3, pp. 190-198, 2012.

[25] P. Calza, C. Medana, E. Padovano, V. Giancotti, and C. Baiocchi, "Identification of the unknown transformation products derived from clarithromycin and carbamazepine using liquid chromatography/high-resolution mass spectrometry," Rapid Communications in Mass Spectrometry, vol. 26, no. 15, pp. 1687-1704, 2012.

[26] L. J. M. Jansen, Y. J. C. Bolck, J. Rademaker, T. Zuidema, and B. J. A. Berendsen, “The analysis of tetracyclines, quinolones, macrolides, lincosamides, pleuromutilins, and sulfonamides in chicken feathers using UHPLC-MS/MS in order to monitor antibiotic use in the poultry sector," Analytical and Bioanalytical Chemistry, vol. 409, no. 21, pp. 4927-4941, 2017.

[27] D. C. Love, R. U. Halden, M. F. Davis, and K. E. Nachman, "Feather meal: a previously unrecognized route for reentry into the food supply of multiple pharmaceuticals and personal care products (PPCPs)," Environmental Science \& Technology, vol. 46, no. 7, pp. 3795-3802, 2012.

[28] The Commission of the European Communities, "Commission decision of 12 August 2002 implementing council directive 96/23/EC concerning the performance of analytical methods and the interpretation of results," Official Journal of the European Communities, vol. L221, pp. 8-36, 2002.
[29] T. Wenzl, J. Haedrich, A. Schaechtele, P. Robouch, and J. Stroka, "Guidance document on the estimation of LOD and LOQ for measurements in the field of contaminants in feed and food," JRC Technical Reports, EUR 28099, Publications Office of the European Union, Luxebourg, 2016. 

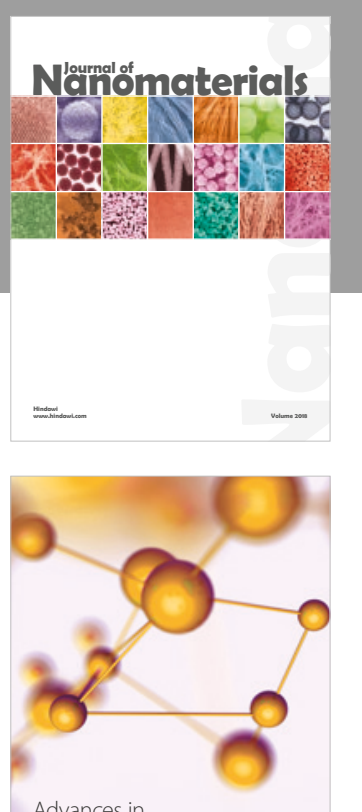

Physical Chemistry
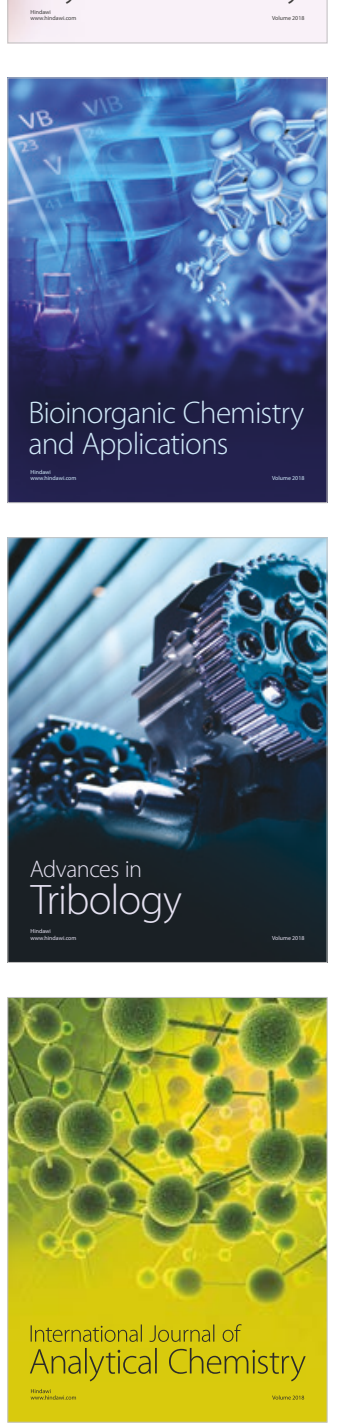

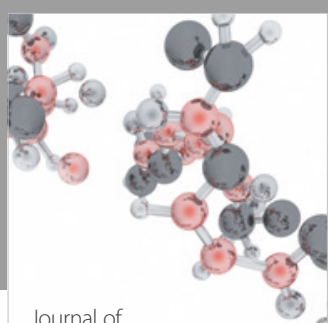

Analytical Methods

in Chemistry

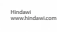

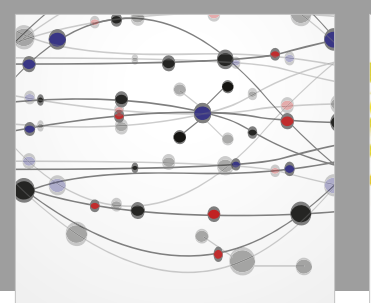

The Scientific World Journal

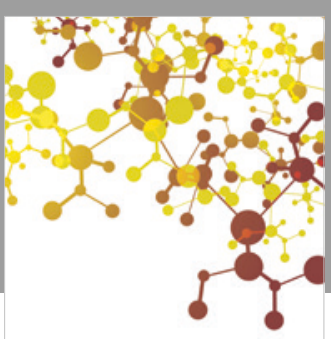

Journal of

Applied Chemistry
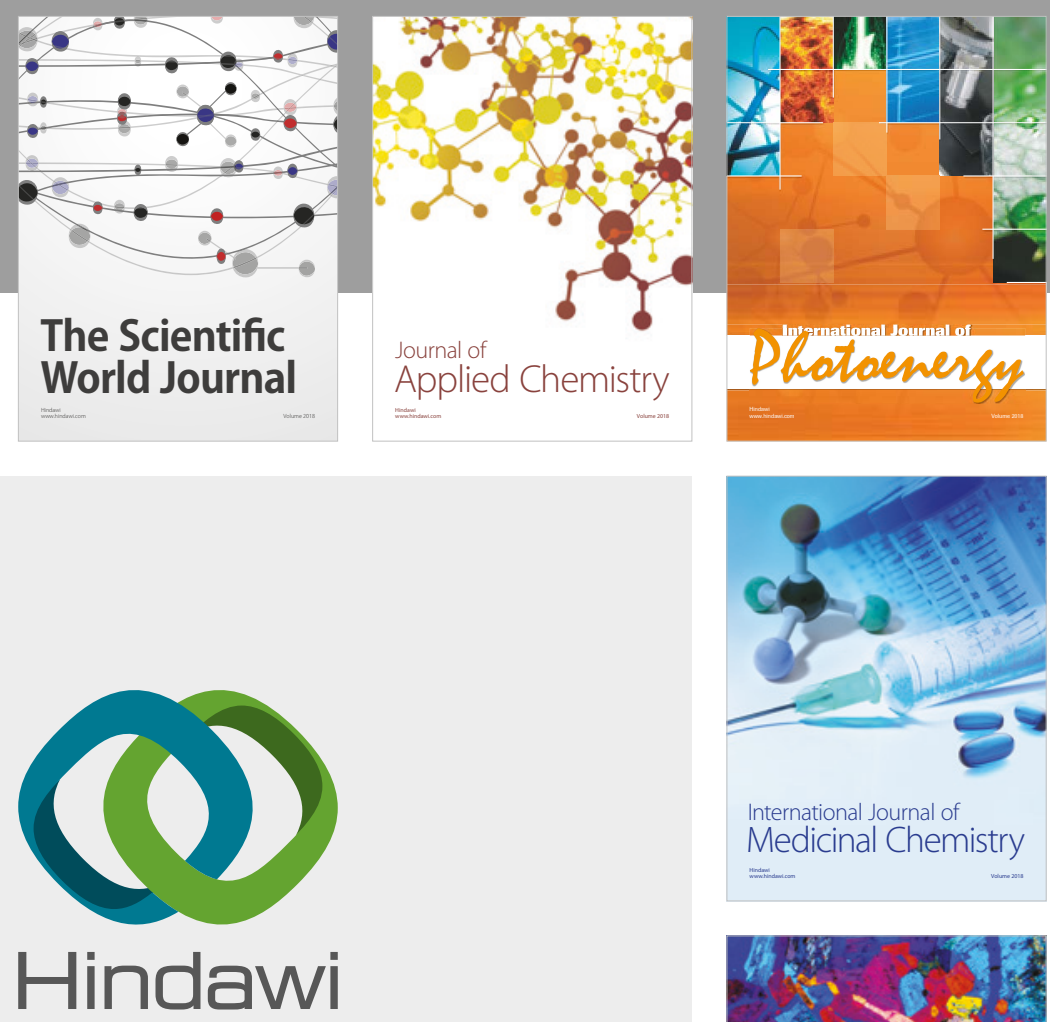

Submit your manuscripts at

www.hindawi.com
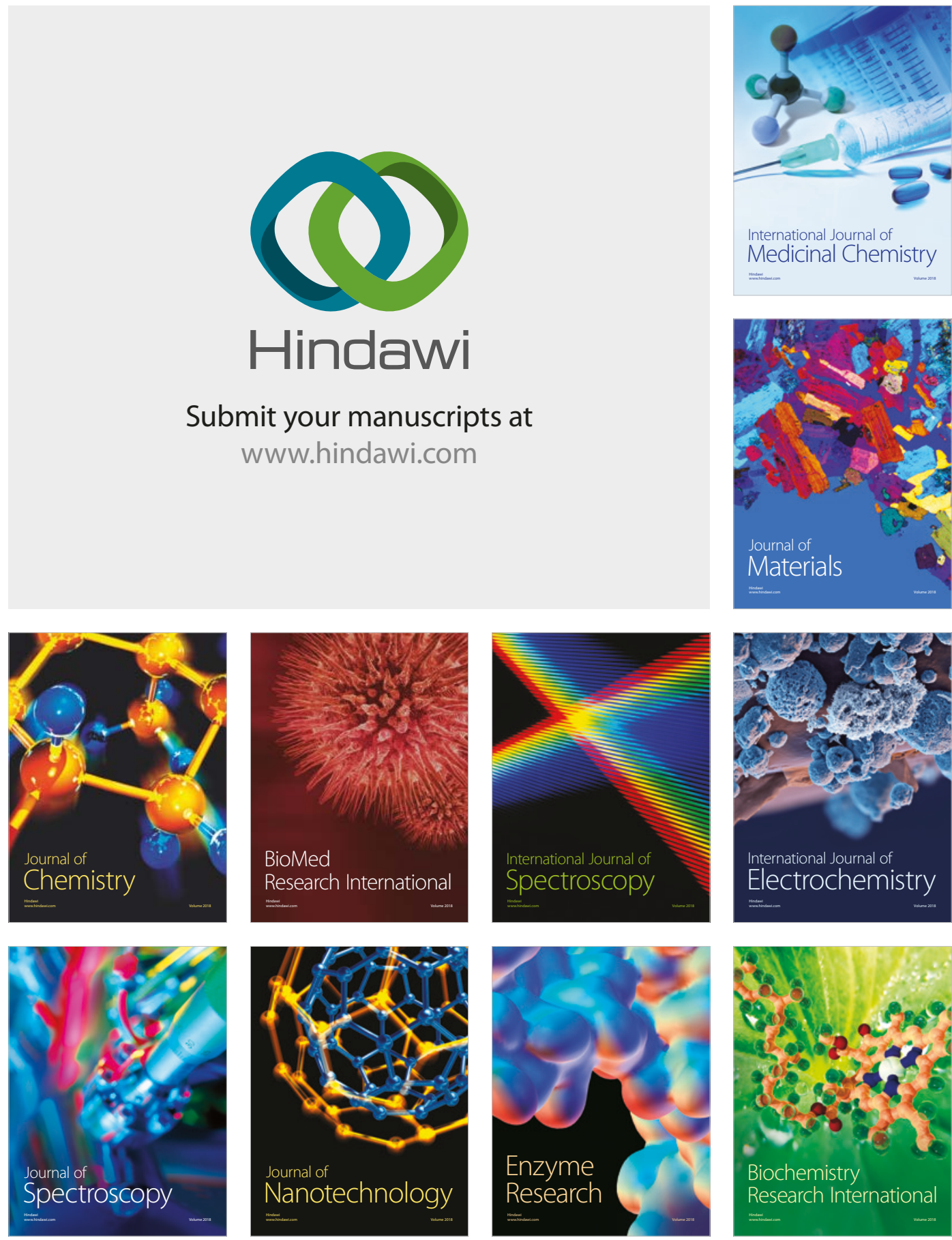
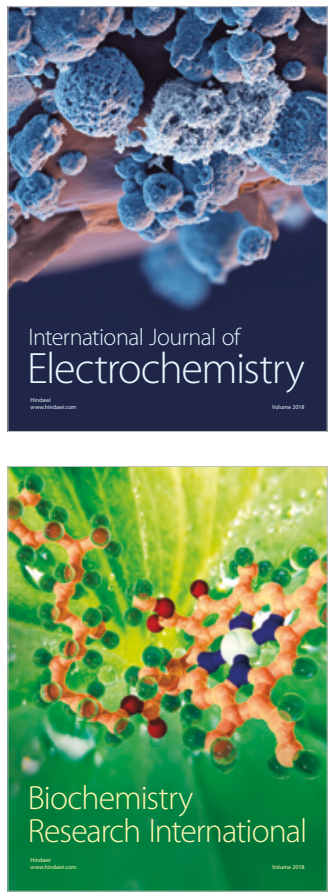